\title{
COMMENTS ON FILAMENT-DISINTEGRATION AND \\ ITS RELATION TO OTHER ASPECTS \\ OF SOLAR ACTIVITY
}

\author{
HELEN W. DODSON and E. RUTH HEDEMAN \\ McMath-Hulbert Observatory, The University of Michigan \\ and
}

MARTA ROVIRA DE MICELI*

San Miguel Observatory, Argentina

(Received 22 November, 1971)

\begin{abstract}
Studies of 'disparitions brusques' in solar cycles 19 and 20 (to 1969) indicate that such events occur frequently. Approximately $30 \%$ of all large filaments in these cycles disintegrated in the course of their transit across the solar disk. 'Major' flares occurred with above average frequency on the last day on which 141 large disappearing filaments were observed (1958-60; 1966-69). Relationships betwcen a disintcgrating filament on July 10-11, 1959, a prior major flare, a newly formed spot, and concomitant growth of $\mathrm{H} x$ plage are presented. Observation of prior descending prominence material apparently directed towards the location of the flare of $1959 \mathrm{July} 15^{\mathrm{d}} 19^{\mathrm{h}} 23^{\mathrm{m}}$ is reported. The development of the filament-associated flare of February 13,1967 is described.
\end{abstract}

\section{Introduction}

Studies of prominences in the course of their transit as filaments across the solar disk can add significantly to information relating to the life histories of prominences and to their possible connection with other solar phenomcza. The relatively sudden disintcgrations of filaments, the 'disparitions brusques', are the disk counterparts of at least some of the phenomena called eruptive or ascending prominences when such events occur at the limb of the Sun.

Statistics for 'disparitions brusques' appear in the tables of the Cartes Synoptiques published at Meudon Obscrvatory. From these statistics, and from daily observations at the McMath-Hulbert Observatory, it is clear that the disintegration of a filament, even a great one, is a common event. In solar cycles 19 and 20 (to 1959) at least 252 large filaments 'disappeared' during the course of transit across the solar disk. These filaments represented approximately $30 \%$ of all filaments evaluated as importance 5 or greater on the Meudon scale. 'Disparitions brusques' were frequent during the years of high solar activity and few in the ycars near solar minimum. These findings are in general accord with the results of study of 'disparitions brusques' in earlier years by M. and L. d'Azambuja (1948). In cycle 19, the greatest number of large filaments and major 'disparitions brusques' occurred in 1959, two years after sunspot maximum. (See Table I and Figure 1.)

* Visiting Astronomer, McMath-Hulbert Observatory. 

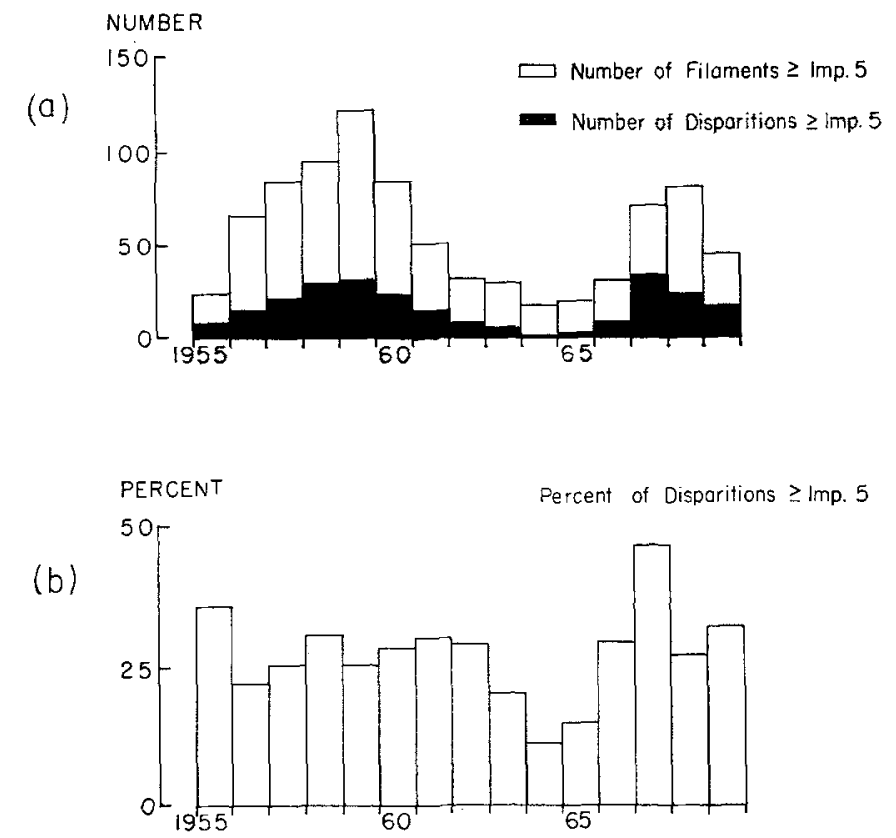

Fig. 1. (a) Number of filaments of importance $>5$ in the Cartes Synoptiques (Meudon), and the number of these filaments that disappeared (disparition brusque) in the course of transit of the solar disk, 1955-1969. (b) Percent of filaments of importance $>5$ that disappeared during disk transit, $1955-1969$.

\section{TABLE I}

Filaments and 'Disparitions brusques', 1955-1969

(From Cartes Synoptiques published by Meudon Observatory)

\begin{tabular}{llcl}
\hline Year & \multicolumn{3}{l}{ Filaments with importance $\$ 5$} \\
\cline { 2 - 4 } & $\begin{array}{l}\text { Total } \\
\text { number }\end{array}$ & \multicolumn{2}{c}{ With disparitions brusques } \\
\hline 1955 & & Number & $\%$ \\
1956 & 25 & 9 & 36 \\
1957 & 67 & 15 & 22 \\
1958 & 84 & 21 & 25 \\
1959 & 94 & 30 & 32 \\
1960 & 121 & 36 & 30 \\
1961 & 84 & 26 & 31 \\
1962 & 50 & 15 & 30 \\
1963 & 31 & 9 & 29 \\
1964 & 30 & 6 & 20 \\
1965 & 18 & 2 & 11 \\
1966 & 20 & 3 & 29 \\
1967 & 31 & 9 & 46 \\
1968 & 71 & 33 & 33 \\
1969 & 81 & 23 & 30 \\
\hline Total & 46 & 15 & 28 \\
\hline
\end{tabular}


The phenomena that precede and follow the activation and subsequent disappearance of major filaments are varied. Years ago, Bruzek $(1952,1957)$ pointed out (1) the frequency of formation of new spots within $25^{\circ}$ of disappearing filaments during the 5 days that preceded the 'disparition brusque', and (2) the occurrence of flares and chromospheric brightenings following activity in certain filaments. Bruzed deduced a velocity of $\sim 1 \mathrm{~km} \mathrm{~s}^{-1}$, or $5^{\circ}-6^{\circ}$ per day, for the transport of a disturbance from newly formed spots to filaments. Furthermore, in 1958, Bruzek suggested that a disturbance travelling at $\sim 50 \mathrm{~km} \mathrm{~s}^{-1}\left(>10^{\circ} \mathrm{h}^{-1}\right)$ from the site of some flares may cause the disruption of certain filaments. This effect is in addition to the more rapidly travelling wave emphasized by Athay and Moreton (1961) that causes the brief winking of certain filaments at the time of flares. The filament that crossed the equator at the time of the great flare of May 10, 1949 apparently experienced both types of flareassociated disturbances. It 'winked' during the flare and 'disappeared' before observations could be resumed on May 11. (Dodson, 1949; Dodson and Hedeman, 1964.)

The association between filament activity and subsequent or concomitant flares has been noted by many investigators, and their work has been summarized and extended by Smith and Ramsey (1964). An interesting example of the brightening of the chromosphere to flare intensity at the apparent place of impact of descending prominence material is provided by the location of the flare of importance $1+, 1959$ July $15^{\mathrm{d}} 19^{\mathrm{h}} 23^{\mathrm{m}}$ UT and that of a prior active prominence observed in projection on
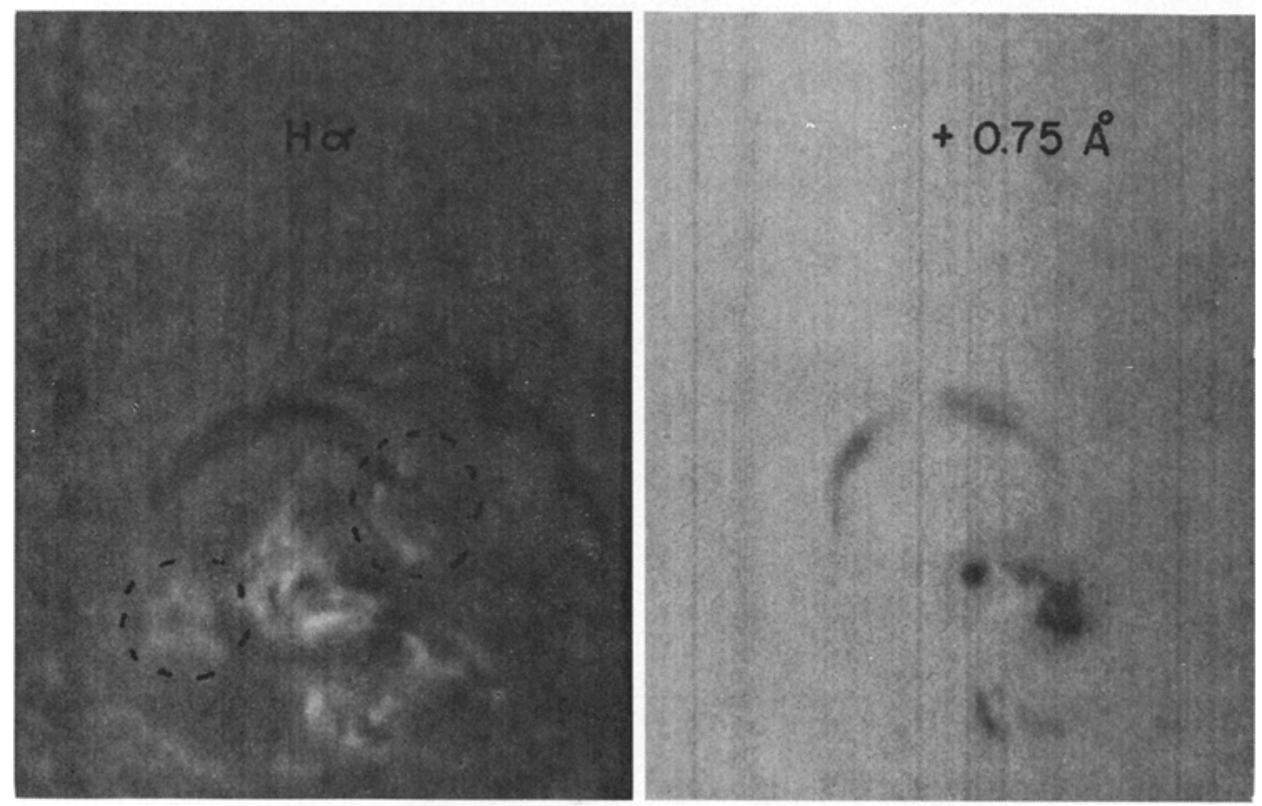

Fig. 2. Left: Ha spectroheliogram 1959 July $15^{\mathrm{d}} 18^{\mathrm{h}} 26^{\mathrm{m}}$ UT showing center of activity with plage and filaments. Dashed lines identify the location of the flare later at $19^{\mathrm{h}} 23^{\mathrm{m}}$ UT. Right: Spectroheliogram $\mathrm{H}_{2} \mid 0.75 \AA$, July $15^{\mathrm{u}} 18^{\mathrm{t}} 28^{\mathrm{m}}$ UT showing portions of filament descending toward solar surface. 
the disk. A relatively large, arcshaped filament was visible on center-of-H $\varkappa$ records from $\sim 18^{\mathrm{h}} 20^{\mathrm{m}}$ to $19^{\mathrm{h}} 03^{\mathrm{m}}$ UT on July 15, 1959. Wavelength-sweep spectroheliograms from $18^{\mathrm{h}} 21^{\mathrm{m}}$ to $18^{\mathrm{h}} 36^{\mathrm{m}}$ show that the prominence, though rising, also was falling back to the solar surface along two paths that apparently were directed, respectively towards two segments of the large $\mathrm{H} \alpha$ plage then at N09. $\mathrm{W} 15^{\circ}$ (See Figure 2). At $19^{\mathrm{h}} 23^{\mathrm{m}} \mathrm{UT}$, approximately one hour after the observed prominence activity, the two plage segments, identified by dashed lines in Figure 2, suddenly increased to flarc intensity. The flare consisted of two separate, relatively round, bright areas. The flare lasted for $28 \mathrm{~min}$ and was accompanied by ionospheric disturbance, distinctive events at radio frequencies, and a group of type III bursts.

\section{Comparison of 'Disparitions Brusques' and Frequency of Flare Occurrence}

Although many large filaments disintegrate without the occurrence of obviously associated prior or subsequent flares (e.g. McCabe, 1970), a study of 'disparitions brusques' of large filaments in solar cycles 19 and 20 indicates that 'major' flares have tended to occur with above average frequency on the last day on which a disappearing filament was observed. (See Figure 3.) Supcrposed values of the Comprehensive Flare Index (Dodson and Hedeman, 1971) have been derived for "major' flares 7 days beforc and 7 days after the disappearance of 141 large filaments in the years 1958-60 and 1966-69. The greatness of the 'disparition brusque' was confirmed in each case by the evaluation in the Cartes Synoptiques (i.e. importance $>5$ ) and by direct examination of the Fraunhofer Solar Maps or spectroheliograms at the McMalh-Hulbert Observatory. The day on which the filament was last seen was taken as day '7cro' in the calculations. For the preceding and following seven days, values of the "Comprehensive Flare Index' for all 'major' flares were tabulated and summed.

The category, 'major' flarc, included all fiares that satisfied any onc of the following

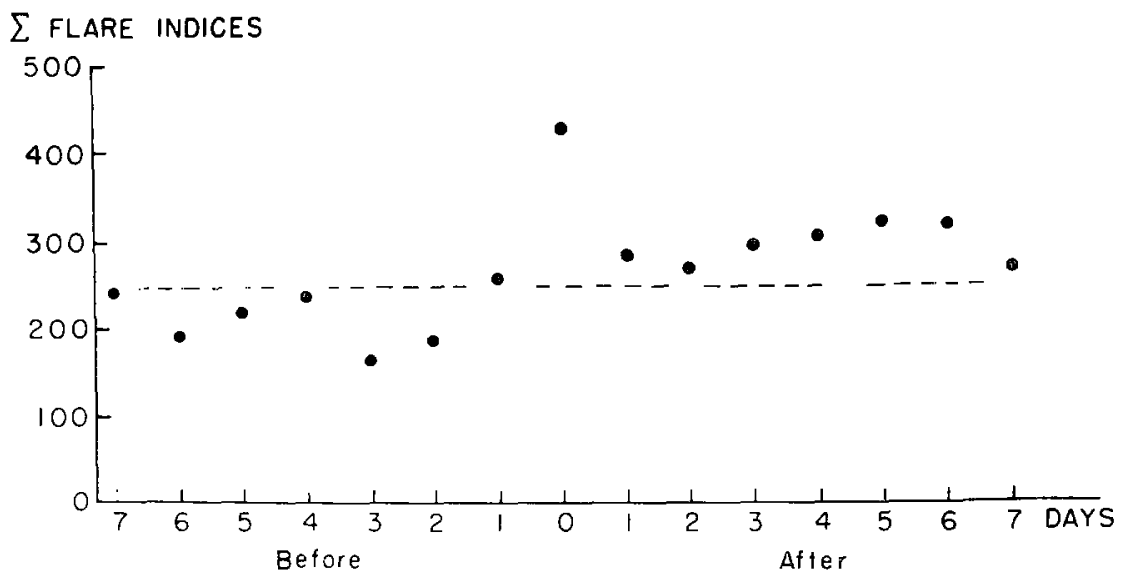

Fig. 3. Summation of Comprehensive Flare Indices for all 'major' flares for seven days bcfore and seven days after the 'disparition brusque' of large filaments, 1958-60 and 1966-69. Day zero is the day the filament was last seen. 
criteria: $\mathrm{H} x$ importance $\geqslant 3$, accompanying ionospheric disturbance of importance $\geqslant 3,10 \mathrm{~cm}$ flux $\geqslant 500 \times 10^{-22} \mathrm{Wm}^{-2}(\mathrm{~Hz})^{-1}$, type II burst, or type IV radiation with duration $>10 \mathrm{~min}$. The results of the calculations are shown in Figure 3 . The sums of the superposed Comprehensive Flare Indices give a high peak on the day the filament was last seen, and slightly higher values on the days following, than on the days preceding, the disappearance of the filament. It should be noted that these figures do not distinguish between cases of major flares on day zero that preceded, and those that accompanied or followed, the disintegration of the filaments.

\section{Observations of Two Disappearing Filaments}

The diversity of phenomena that sometimes attend the disappearance of filaments or eruptive prominences can be illustrated by consideration of the circumstances apparently related to specific instances of the disintegration of large filaments. The observations suggest that prominence activity may be playing a broad role in several aspects of solar activity.

A. DISINTEGRATING FILAMINN, JULY 10-11, 1959, AND $\Lambda$ GROWING CENTIR OF: ACTIVITY

The existence of the 'continuous' $\mathrm{H} x$ record of the Sun, prepared through interna-

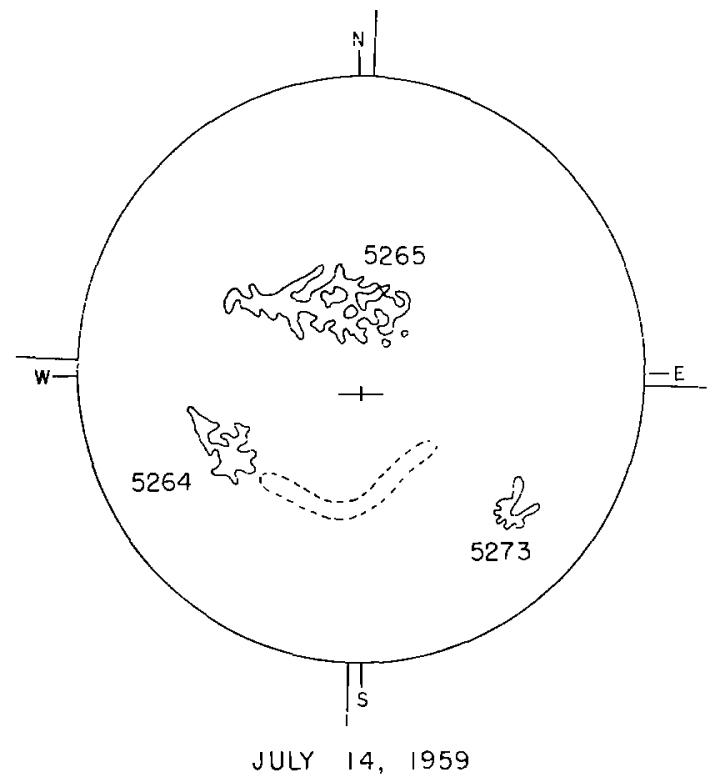

Fig. 4. Diagram of the Sun on 1959 July 14 showing three of the principal calcium plages and the position (in dashed lines) that a large filament would have occupied, had it nol disintegratcd, July 10-11. Region 5265 was the site of many great flares July 10-16; region 5264 grew as the filament disintegrated; region 5273, without large spots, was the site of large flares on July 13 and 14. 
tional cooperation by $\mathrm{H}$. Smith at Sacramento Peak Observatory, for two weeks in July 1959, suggested the suitability of this interval for the study of a disappearing filament and its large scale attendant phenomena. Fortunately, a relatively large filament disintegrated during the days July 10 and 11, and the phenomenon can be followed on the continuous film and, in part, on the McMath-Hulbert records. On July 10 this filament was centered at $\sim \mathrm{S} 24^{\circ} \mathrm{E} 53^{\circ}$. It was in the same longitude as the great flare-rich center of activity of July 1959 (McMath plage 5265), but on the opposite side of the equator. (See Figure 4.) The area of the filament, in units of the solar disk, has been measured on center-of-H $\alpha$ pictures. The results are shown in Figure 5.

In the early hours of July 10 a flare of outstanding magnitude, importance $3+$, occurred in the great center of activity $\sim 37^{\circ}$ to the North of the filament. The flare lasted for more than $7 \mathrm{~h}$. By the early hours of July 11 , the filament in the south was clearly diminishing in size. There may or may not be a relationship betweenthe occurrence of the great flare and the subsequent disappearance of the filament.

Additionally, a new spot had formed on July 10 close to the western tip of the filament. The spot was visible by $12^{\text {h }}$ UT on July 10. Throughout the remainder of
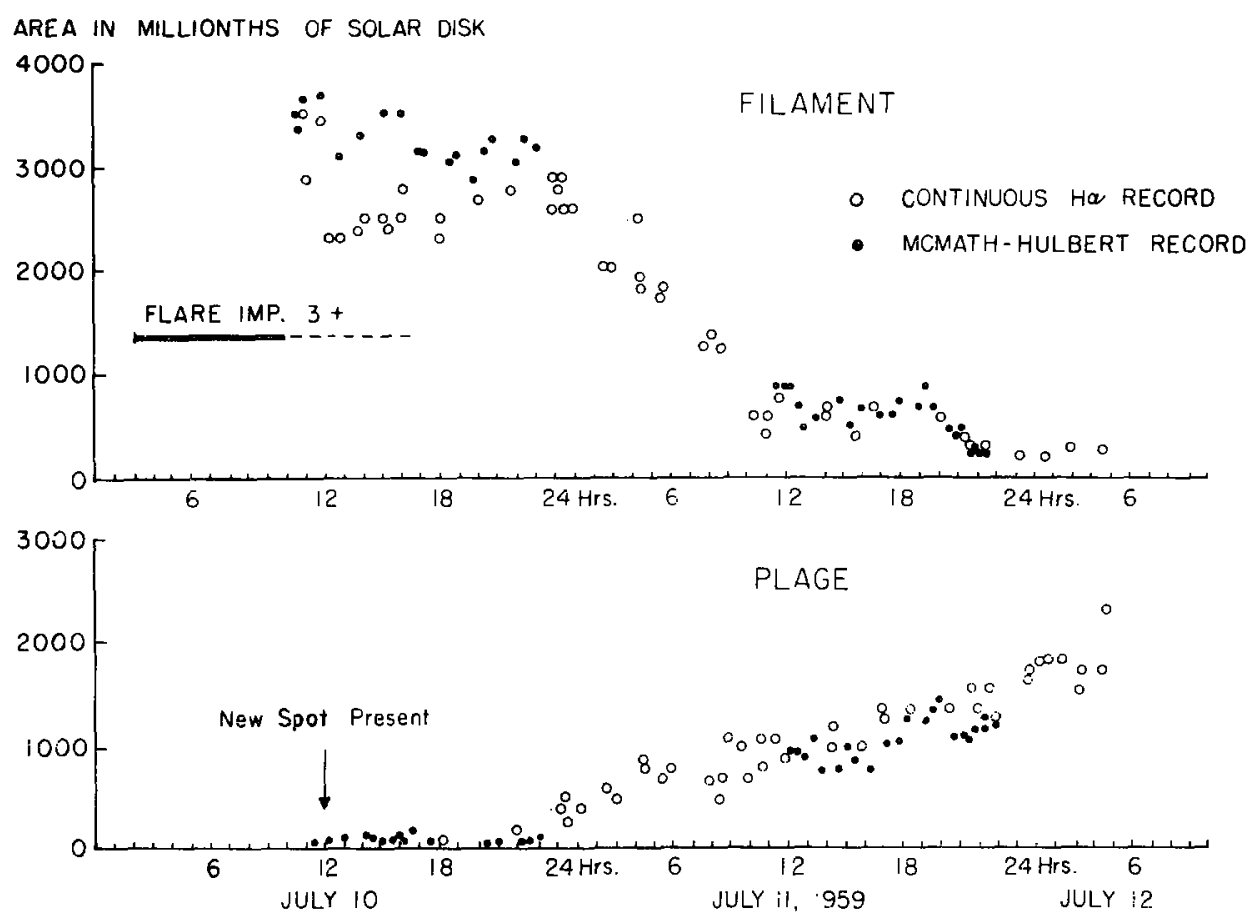

Fig. 5. Diagrams showing the time relationships of the disintegration of a filament, the occurrence of a large flare, the formation of a new spot and the growth of the associated plage. Top: Measurements of area of the filament in millionths of the solar disk on center of Ha records, July 10-11, 1959. Bottom: Measurements of arca of $\mathrm{H} \alpha$ plage (5264) in millionths of solar disk, July 10-11, 1959. 
July 10 , the $\mathrm{H} x$ plage associated with the new spot was not bright and did not increase in area. According to our measurcments, the plage (McMath 5264) began to increase in intensity and grow in area simultaneoulsy with the onset of disintegration of the adjacent filament. (See Figure 5.) The filament disintegration continued during a $20 \mathrm{~h}$ interval.

In 1952 Bruzek wrote that the formation of a spot in the vicinity of a filament is followed, almost without exception, by the immediate disappearance of the latter, or at least by its shrinking in size. The 'disparition brusque' of July 10-11, 1959 fits this pattern. Furthermore, the increase in size and brightness of the plage, concomitant with the interval of disintegration of the filament, recalls the numerous reports of chromospheric brightenings in association with 'disparitions brusques'. The pictures of the growing plage on July 11 show that it extended in a direction that merged with the western tip of the disintegrating filament, and gave an impression of association between the two phenomena. The formation of the spot may have upset the stability of the filament and initiated its disintegration. Descending promincnce material, as part of the disintegration of the filament, may have facilitated the growth and brightening of the plage (Dodson and Hedeman, 1952; Hyder, 1967).

\section{B. DISINTEGRATING FILAMENT, FiBRUARY 13, 1967, AND ASSOCIATED FlaRT:}

The greatness of flares that are sorretimes associated directly with the disparitions brusques' of filaments can be illustrated by the flarc of importance 3 at $17^{\mathrm{h}} 47^{\mathrm{m}} \mathrm{UT}$ on February 13, 1967. (Sec Solar Physics 13, 408.) This flare consisted of two or more bright ribbons that followed closely the position of a large previously existing dark filament. The flare and filament crossed a bright plage in a declining center of activity. The associated spot had diminished to minute umbrae that fluctuated in visibility from day to day. On February 13 there were two tiny umbrac, each no larger than 3 millionths of the solar hemisphere. There is no confirmed evidence for the formation of an enduring spot in the neighborhood of this filament in the hours or days just prior to its disintegration.

The region in which the filament and flare occurred was McMath plage 8687 , which has been identified (Dodson and Hedeman, 1969) as the possible site on the invisible hemispherc, of the source of energetic cosmic rays on January $28,1967$. The flare was bright and very large. It rose to maximum relatively slowly (33 min from start to maximum) and was of long duration $\left(3^{\mathrm{h}} 43^{\mathrm{m}}\right)$. The most unusual featurc of the event, other than the great size of the $\mathrm{H} x$ flare, was the extent of the associated filament. According to McMath-Hulbert observations and those reported by Shimabukuro (1968), the first signs of activity in the region were pre-flare brightenings that took place at $\sim 17^{\mathrm{h}} 00^{\mathrm{m}}$ UT. By $17^{\mathrm{h}} 30^{\mathrm{m}}$ the dark filament showed motion, and by $17^{\mathrm{h}} 47^{\mathrm{m}}$ the flare had started. The disintegration of the filament, on center of $\mathrm{H} x$ records, began during the first $8 \mathrm{~min}$ of the $\mathrm{H} x$ flare and before the marked growth in area of the flaring regions occurred.

This filament-associated flare in a center of activity with almost no spots was accompanied by radio frequency bursts of types II, III, and IV. At $10 \mathrm{~cm}$ the peak flux 
was only $50 \times 10^{-{ }^{22}} \mathrm{Wm}^{-2}(\mathrm{~Hz})^{-1}$ and the cvent did not have a U-type burst (Castelli et al., 1967). Nevertheless protons with energies $\geqslant 19 \mathrm{MeV}$ were observed within $2 \mathrm{~h}$ by satcllites, and PCA was recorded (Masley and Goedike, 1968). Study of the X-ray spectrum of this flare by Walker and Rugge (1968) revealed strong enhancement of lines of high ionization potential (Fexvil, Nex, Mgxı, FexvIII, and NixIX). The flare was followed in slightly less than 2 days (February 15) by the onset of a severe, geomagnetic storm with sudden commencement. Satcllites recorded the concomitant arrival of protons with energies greater than $90 \mathrm{McV}$. Additionally Hirshberg et al. (1969) report increased helium to hydrogen ratio in the solar wind, February 15 and $16,1967$.

The filament-associated flare of February 13, 1967 was an example of a great isolated major flare in a declining center of activity. Its occurrence did not lead to a resurgence of activity in the region in subscquent days or rotations. If one believes that the energy of a flare stems ultimately from a loss of magnetic energy, then the occurrence of such filament-associated flares in old and dying regions is a visible demonstration that the region is losing magnetic energy. From this point of view, filament disintegration and flare occurrence may be considered to represent one aspect of the probably complex process by which centers of activity finally disappear.

\section{Discussion}

The frequent occurrence of filament-disintegration and the vast extent of this phenomenon on the solar surface suggest that such events warrent more than casual consideration in overall studies of solar activity. Filaments, born in one center of activity, (d'Azambuja, 1948) perhaps disrupted by the formation of a neighboring spot or flarc, apparently may contribute to the brightening of another center of activity. From time to time, filaments apparently act as liason between individual centers of activity, and play a role in the growth of large activity zones. It secms of interest that the great July 1946 center of activity (CMP July 27), with the third largest spot since 1874, developed in the midst of a filament 7 rotations old, that had drifted $\sim 100^{\circ}$ in longitude from its origin in the neighborhood of the second largest of all known spots (CMP, February 6, 1946) (see Cartes Synoptiques and Greenwich Photoheliographic Results). The drift of great filaments marks the migration of old magnetic fields. The descending prominence material of a disintegrating filament apparently results in transient brightening of the chromosphere or sometimes in the occurrence of a great flare, or the rapid growth of a center of activity.

There is growing evidence that single centers of activity or single flares should not be considered as isolated, independent phenomena. The various aspects of solar activity, even at relatively great separations on the solar surface appear, at times, to have a dependence one on the other (Wild, 1969). In studies of the formation of zones of activity and in surveys of the evolutional development of the solar cycle, it would seem appropriate to give duc consideration to the possible role of the large filaments, their disintegration, and their reformation. 


\section{Acknowledgements}

This research was supported in part by the National Aeronautics and Space Administration Contract NGL-23-005-275.

\section{References}

d'Azambuja, M. and L.: 1948, Ann. Obs. Paris, Meudon 6, Fasc. VII.

Athay, R. G. and Moreton, G. E.: 1961, Astrophys. J. 133, 935.

Bruzek, Anton: 1952, Z. Astrophys. 31, 99.

Bruzek, Anton: 1957, Z. Astrophys. 42, 76.

Bruzek, Anton: 1958, Z. Astrophys. 44, 183.

Castelli, John P., Aarons, J., and Michael, G. G.: 1967, J. Geophys. Res. 72, 5491.

Dodson, Helen W.: 1949, Astrophys. J. 110, 382.

Dodson, Helen W. and Hedeman, E. R.: 1952, Observatory 72, 30.

Dodson, Helen W. and Hedeman, E. R.: 1964, Report AAS-NASA Symposium on the Physics of Solar Flares, p. 15.

Dodson, Helen W. and Hedeman, E. R.: 1969, Solar Phys. 9, 278.

Dodson, Helen W. and Hedeman, E. R.: 1971, An Experimental, Comprehensivc Flare Index and Its Derivation for 'Major' Flares, 1955-1969; U.A.G.-14, World Data Center A, Boulder, Colo.

Hirshberg, J., Alksne, A., Colburn, D. S., Bame, S. S., and Hundhausen, A. J.: 1970, J. Geophys. Res. 75, 1.

Hyder, C. L.: 1967, Solar Phys. $2,49$.

Masley, A. J. and Goedike, A. D.: 1968, Can. J. Phys. 46, 766.

McCabe, Marie: 1970, Solar Phys. 12, 115.

Shimabukuro, F. I.: 1968, Solar Phys. 5, 498.

Smith, Sara F. and Ramsey, Harry E.: 1964, Z. Astrophys. 60, 1.

Walker, A. B. C. and Rugge, H. R.: 1968, in C. de Jager and Z. Švestka (eds.), 'Solar Flares and Space Research', COSPAR Symposium, p. 102.

Wild, J. P.: 1969, Proc. Astron. Soc. Australia 1, 181.

\section{Data Sources}

Cartes Synoptiques de la Chromosphere Solaire et Catalogue des Filaments de la Couche Superieure, published by Observatoire de Paris, Section d'Astrophysique at Meudon.

Greenwich Photoheliographic Results, published by the Royal Greenwich Observatory.

Solar-Geophysical Data Bulletin, Solar World Data Center A, Upper Atmospherc Geophysics, NOAA, BouIder, Colo. 